\title{
A Calcium Flux Is Required for Circadian Rhythm Generation in Mammalian Pacemaker Neurons
}

\author{
Gabriella B. Lundkvist, ${ }^{1}$ Yongho Kwak, ${ }^{1}$ Erin K. Davis, ${ }^{1}$ Hajime Tei, ${ }^{2}$ and Gene D. Block ${ }^{1}$ \\ ${ }^{1}$ Center for Biological Timing, Department of Biology, University of Virginia, Charlottesville, Virginia 22903, and ${ }^{2}$ Research Group of Chronogenomics, \\ Mitsubishi Kagaku Institute of Life Sciences, Machida, Tokyo 194-8511, Japan
}

Generation of mammalian circadian rhythms involves molecular transcriptional and translational feedback loops. It is not clear how membrane events interact with the intracellular molecular clock or whether membrane activities are involved in the actual generation of the circadian rhythm. We examined the role of membrane potential and calcium $\left(\mathrm{Ca}^{2+}\right)$ influx in the expression of the circadian rhythm of the clock gene Period 1 (Per1) within the rat suprachiasmatic nucleus (SCN), the master pacemaker controlling circadian rhythmicity. Membrane hyperpolarization, caused by lowering the extracellular concentration of potassium or blocking Ca ${ }^{2+}$ influx in SCN cultures by lowering $\left[\mathrm{Ca}^{2+}\right]$, reversibly abolished the rhythmic expression of Per1. In addition, the amplitude of Per1 expression was markedly decreased by voltage-gated $\mathrm{Ca}^{2+}$ channel antagonists. A similar result was observed for mouse Per1 and PER2. Together, these results strongly suggest that a transmembrane $\mathrm{Ca}^{2+}$ flux is necessary for sustained molecular rhythmicity in the SCN. We propose that periodic $\mathrm{Ca}^{2+}$ influx, resulting from circadian variations in membrane potential, is a critical process for circadian pacemaker function.

Key words: circadian rhythm; calcium; potassium; suprachiasmatic nucleus; Period 1; PERIOD 2

\section{Introduction}

The hypothalamic suprachiasmatic nucleus (SCN) plays a critical role in controlling mammalian circadian rhythmicity. Although other brain regions and non-neural tissues express circadian rhythms in molecular expression (Yamazaki et al., 2000; Abe et al., 2002), the SCN plays a pervasive role in the generation and control of physiological and behavioral rhythms (Moore, 1991). SCN rhythm generation is a cell-autonomous property (Welsh et al., 1995). Several genes, including Period (Per1, Per2, and Per3) and Cryptochromes (Cry1, Cry2), have been identified that play critical roles in generating circadian rhythms. Although models of the mammalian clock continue to evolve, periodicity is presently believed to be generated by an autoregulatory transcriptional and posttranslational feedback loop involving "clock genes" and their products (Dunlap, 1999). Membrane phenomena, such as electrical impulses and ionic currents, have not been generally recognized as part of the core clock mechanism but rather as part of the pathways by which environmental synchronizing signals reach the clock (Block et al., 1993; Meijer and Schwartz, 2003) and by which the clock regulates tissue and organ targets (Schaap et al., 2003). This view has been challenged in Drosophila, in which silencing of electrical activity leads to arrhythmic expression of the PERIOD and TIMELESS proteins, core constituents of the circadian clock in Drosophila (Nitabach

Received Jan. 30, 2005; revised July 3, 2005; accepted July 5, 2005.

This work was supported by National Institutes of Health Grants HL71510 and MH62517 (G.D.B.) and by funds from the Royal Swedish Academy of Sciences (G.B.L.). We thank Dr. Joseph Takahashi (Northwestern University) for supplying the PER2 transgenic mouse.

Correspondence should be addressed to Gene D. Block, Center for Biological Timing, Department of Biology, University of Virginia, Charlottesville, VA 22903. E-mail: gdb@virginia.edu.

DOI:10.1523/JNEUROSCI.2211-05.2005

Copyright $\odot 2005$ Society for Neuroscience $\quad 0270-6474 / 05 / 257682-05 \$ 15.00 / 0$ et al., 2002). These data raise the issue of whether electrical activity and underlying ionic fluxes play a more central role in rhythm generation.

We now provide data suggesting that a transmembrane calcium $\left(\mathrm{Ca}^{2+}\right)$ flux is critical for molecular rhythmicity within the mammalian SCN and at least one peripheral oscillator, the liver. We used a luciferase reporter to assay real-time clock gene activity in tissue cultures. Preventing $\mathrm{Ca}^{2+}$ influx by hyperpolarizing SCN neurons, removing extracellular $\mathrm{Ca}^{2+}$, or applying $\mathrm{Ca}^{2+}$ channel blockers leads to a loss of rhythmic expression of Per1 and PER2. The apparent requirement for $\mathrm{Ca}^{2+}$ influx to maintain rhythmicity reveals an unforeseen role for ionic currents in mammalian circadian rhythm generation.

\section{Materials and Methods}

Animals. A Per1-luciferase transgenic rat line [W(per1)1], a Per1luciferase transgenic mouse line (C57x+/-) (Dr. Hajime Tei, Mitsubishi Kagaku Institute of Life Sciences) and a PER2:LUCIFERASE knock-in mouse line (provided by Dr. Joseph Takahashi, Department of Neurobiology and Physiology, Northwestern University, Evanston, IL) were raised at the University of Virginia, Department of Biology. The animals were kept on a $12 \mathrm{~h}$ light/dark cycle. All animal use was conducted in accordance with the recommendations of the Committee on Animal Care and Use at the University of Virginia.

Dispersed cell culture procedure. SCNs were punched out with a $440 \mu \mathrm{m}$ diameter neural punch from selected coronal sections $(275 \mu \mathrm{m})$ obtained from 3- to 7-d-old transgenic rat pup brains. The punches were incubated with papain enzyme (Sigma, St. Louis, MO), dissociated by trituration, dispersed on coverslips (1000-3000 cells/slip; glass or Thermanox), coated with laminin $(5.8 \mu \mathrm{g} /$ coverslip) and poly-D-lysine $(0.02 \mathrm{mg} / \mathrm{ml})$ (Sigma), and kept in $95 \% \mathrm{O}_{2}-5 \% \mathrm{CO}_{2}$. Half of the medium [containing $10 \mathrm{~g} / \mathrm{L}$ DMEM 2902 (Invitrogen, Grand Island, NY), 10\% B27, 84 mм NaHCO, 180.2 mм D-glucose, $0.25 \%$ penicillin-streptomycin, $\mathrm{pH} 7.2-7.3$, osmolarity 290 mOsm) was exchanged three times each week. 
A

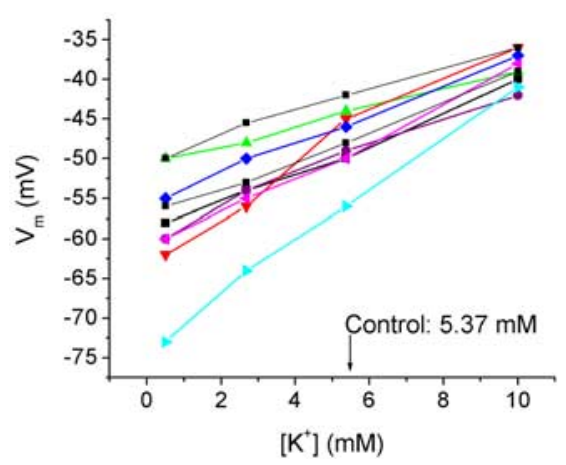

B

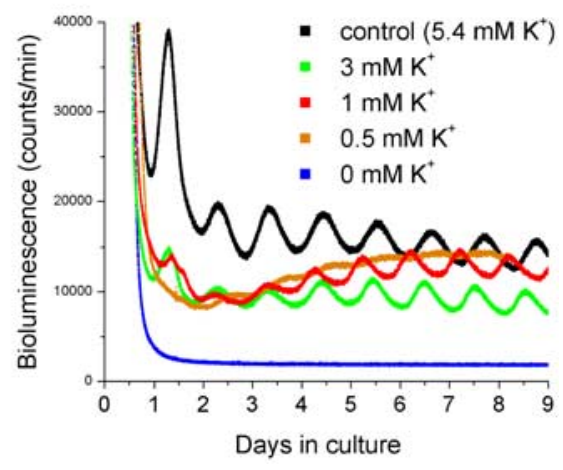

Figure 1. SCN recordings of membrane potential and bioluminescence of Per1-luc expression in various levels of [K $\left.{ }^{+}\right] . \boldsymbol{A}_{\text {, }}$ Current-clamp recordings in culture medium containing $0.5,2.7,5.4$ (control), or $10 \mathrm{~mm} \mathrm{~K}^{+}$. Each color represents membrane potential in a single neuron in various levels of $\left[\mathrm{K}^{+}\right]$. $\boldsymbol{B}$, Bioluminescence recordings from explants obtained from transgenic Per1-luc rats. The explants were cultured in $0,0.5,1,3$, or $5.4 \mathrm{~mm} \mathrm{~K}^{+}$.

Explant cultures. Rats and mice, 2-3 months of age, were anesthetized with $\mathrm{CO}_{2}$ and decapitated. The brains were removed, hypothalamic coronal sections (rat, $300 \mu \mathrm{m}$; mouse, $250 \mu \mathrm{m}$ ) were cut using a vibroslicer, and bilateral or unilateral SCNs were explanted. The explants were placed on culture membranes (Millicell-CM, PICM030-50; Millipore, Bedford, MA) in 35 $\mathrm{mm}$ Petri dishes with $1.2 \mathrm{ml}$ of culture medium [pH 7.2; serum-free, lowsodium bicarbonate, no phenol red; manufactured at the University of Virginia according to the recipe of DMEM (13000-021; Invitrogen)] supplemented with 10 mM HEPES (Sigma), B27 (2\%; 17504-010; Invitrogen), 0.1 mM luciferin (beetle luciferin, potassium salt; Promega, Madison, WI), and antibiotics (25U/ml penicillin, $25 \mathrm{mg} / \mathrm{ml}$ streptomycin; Sigma). The dishes were sealed with cover glasses and vacuum grease and transferred to the recording environment (Yamazaki et al., 2000).

Bioluminescence measurements. Bioluminescence was measured with photomultiplier tube (PMT) detector assemblies (HC135-11 MOD; Hamamatsu, Shizuoka, Japan) modified from HC135-01. The modules and cultures were maintained in light-tight incubators at $36^{\circ} \mathrm{C}$ and interfaced to IBM (White Plains, NY) personal computers for continuous data acquisition. The PMTs were positioned $\sim 1 \mathrm{~cm}$ above the cultures. Photon counts were made through the glass coverslip and integrated over 1 min intervals (Yamazaki et al., 2000).

Whole-cell patch-clamp recordings. The culture medium was replaced with a physiological recording solution containing the following (in mM): $0.81 \mathrm{MgSO}_{4}, 5.37 \mathrm{KCL}, 1.8 \mathrm{CaCl}_{2}, 110 \mathrm{NaCl}, 0.79 \mathrm{NaH}_{2} \mathrm{PO}_{4}, 10.0$ HEPES, 4.19 $\mathrm{NaHCO}_{3}$, and $25.0 \mathrm{D}$-glucose (Sigma). Osmolarity and pH were adjusted to 290-300 mOsm and 7.3, respectively. Patch-clamp pipettes (resistance, 3-6 M 2 ) were filled with a solution containing the following (in $\mathrm{mm}$ ): $140 \mathrm{~K}^{+}$-gluconic acid, 4.0 NaCl, $10 \mathrm{HEPES}, 0.38$ $\mathrm{CaCl}_{2}, 5 \mathrm{EGTA}$, and $0.49 \mathrm{MgCl}_{2}$ (osmolarity, $280 \mathrm{mOsm}$; pH 7.3). Gigaseal formation was achieved by monitoring changes in current responses to voltage pulses. Membrane rupture was made by syringe suction. Resting potentials were recorded in current-clamp mode with an Axoclamp 2A amplifier (Molecular Devices, Foster City, CA) in conjunction with a digital interface (Digidata 1200; Molecular Devices) and read directly from the amplifier. Data acquisition was performed using pClamp 8.0 software (Molecular Devices). For each recording, the physiological solution in the dish was exchanged several times with three different solutions containing different concentrations of $\mathrm{K}^{+}$or $\mathrm{Ca}^{2+}$. For the three different solutions, designated as 1 (control; high [ion] solution), 2 (medium [ion] solution), and 3 (low [ion] solution), the recording in each concentration and each cell was performed in the following order: 1, 2, 3, 2, 1, 2, 3. The average resting potential in each solution $(1,2$, or 3$)$ was then obtained for each cell and used as one data point.

Drugs. Drugs were solubilized in water or dimethylsulfoxide (DMSO; Sigma) to make stock solutions $10-1000 \times$ the working solutions, which were added at the time of culture, except for $\mathrm{Ca}^{2+}$ channel antagonists, which were added after 3-5 d in culture. Equivalent volumes of medium compared with the volume of the added drugs were discarded so the total

volume of medium in cultures was always 1.2 ml. All medium changes and drug manipulations were done manually by manipulating volumes directly in the dish with a pipette in sterile environment outside the recording incubator. Drugs used were tetrodotoxin (TTX; sodium channel blocker; Sigma), $\omega$-agatoxin IVA, $\omega$-agatoxin TK (P/Q-type $\mathrm{Ca}^{2+}$ channel blockers), $\omega$-conotoxin GVIA (N-type blocker), $\omega$-conotoxin MVIIC (Q-type blocker), $\omega$-grammotoxin SIA (N- and P-type blocker), and pimozide ( $\mathrm{T}$ type channel blocker; Alomone Labs, Jerusalem, Israel).

Data analysis. Period analysis was performed with software (written by Dr. Y. Kwak, Department of Biology, University of Virginia) calculating the $2 \mathrm{~h}$ running average of photon counts. Peaks (defined as maximum) were selected, and the time between two peaks was defined as the period during one cycle. For statistical comparisons of periods, the average periods of a minimum of four cycles and a maximum of eight cycles and SEM for each treatment were calculated. A Student's $t$ test was used to calculate the $p$ values.

\section{Results}

\section{Decreasing $\left[\mathrm{K}^{+}\right]$causes membrane hyperpolarization and} stops the Perl oscillation

We used transgenic rats to measure rhythmic Per 1 expression. In these animals, a reporter for the firefly enzyme luciferase $(l u c)$ has been linked to the mouse Per1 promoter (Yamazaki et al., 2000), enabling real-time assay of Per1 expression by recording luciferase activity. To examine the effects of membrane hyperpolarization on SCN Per1 rhythmicity, we prepared SCN slice cultures maintained in culture media containing different $\left[\mathrm{K}^{+}\right]$. In parallel experiments, we performed patch-clamp recordings to examine the effects of lowering $\left[\mathrm{K}^{+}\right]$on membrane potential $(n=9)$. Dispersed SCN neurons recorded in control medium $(5.4 \mathrm{~mm}$ $\left.\left[\mathrm{K}^{+}\right] ; n=20\right)$ had an average resting potential of $-49.8 \pm 1.41$ $\mathrm{mV}$. In 0.5 and $2.7 \mathrm{~mm}\left[\mathrm{~K}^{+}\right]$, the cells were markedly hyperpolarized $(-58.2 \pm 2.33 \mathrm{mV} ;-53.3 \pm 1.77 \mathrm{mV})$ and depolarized in $10 \mathrm{mM}\left[\mathrm{K}^{+}\right](-38.7 \pm 0.71 \mathrm{mV})$ (Fig. $\left.1 A\right)$. In SCN tissue cultures, the Per1-luc signals showed a robust circadian expression with an average period of $25.4 \pm 0.11 \mathrm{~h}(n=12)$. When $\left[\mathrm{K}^{+}\right]$was lowered, we found that the amplitude of the Perl-luc signal decreased. In $0 \mathrm{mM} \mathrm{K}^{+}$(defined as $0 \mathrm{mM} \mathrm{K}^{+}$added to the culture medium), no rhythm in Perl expression could be detected (Fig. $1 B)$. This effect was reversible, and the Perl rhythm could be restored by washing with control medium.

To evaluate whether hyperpolarizing the SCN "stops the clock," in three repeated experiments, we cultured three SCN explants in medium containing $0 \mathrm{mM} \mathrm{K}^{+}$for 18,24 , and $30 \mathrm{~h}$ before replacing with control medium. We reasoned that if the clock was stopped, each rhythm would return after 18, 24, and $30 \mathrm{~h}$, respectively, when $0\left[\mathrm{~K}^{+}\right]$medium was replaced with control medium. As a control, the Per1-luc rhythms were recorded from three explants that were initially cultured in control medium, which was replaced with fresh control medium after 18, 24, and 30 h. The Per1-luc rhythms in the control slices were expressed in phase with each other and remained in phase after replacement with fresh control medium (Fig. 2A). In contrast, in the three explants started in $0\left[\mathrm{~K}^{+}\right]$, there was no evidence of Per 1 rhythmicity until the tissue culture medium was exchanged with control medium. Furthermore, we found that the restored Per1- 
A

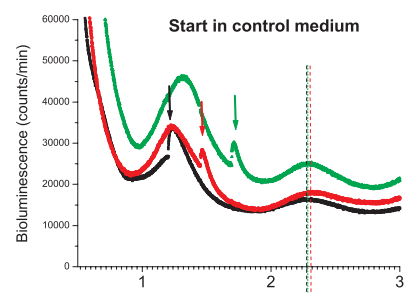

B

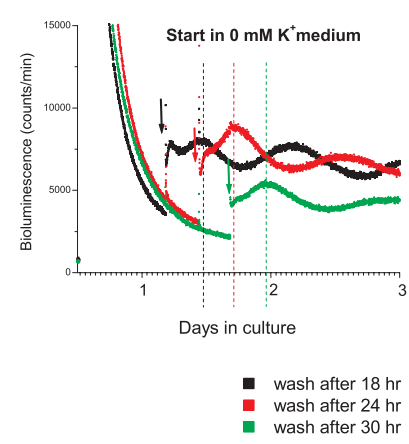

Figure 2. Example of $\mathrm{SCN}$ phase delays in hyperpolarizing medium. $\boldsymbol{A}$, Bioluminescence recordings from three explants in control medium represented by green, red, and black traces. The control medium was replaced with fresh control medium at $6 \mathrm{~h}$ intervals the second day in culture (indicated by arrows), and the phases were compared using the first peaks after medium replacement as reference points (indicated by dashed lines). B, Bioluminescence recordings from three bilateral explants in medium containing $0 \mathrm{~mm} \mathrm{~K}^{+}$, represented by green, red, and black traces. The $0\left[\mathrm{~K}^{+}\right]$medium was replaced with control medium at $6 \mathrm{~h}$ intervals the second day in culture (indicated by arrows). Dotted lines indicate the peaks of the Per1-luc signals after medium replacement.

luc rhythms in the three cultures were $6 \mathrm{~h}$ out of phase from one another, suggesting that the motion of the clock, as measured by Per1-luc rhythmicity, was stopped in the $0\left[\mathrm{~K}^{+}\right]$environments (Fig. 2B).

\section{Decreasing $\left[\mathrm{Ca}^{2+}\right]$ abolishes the Per1 rhythm in the SCN and liver}

Depolarization of SCN neurons causes influx of $\mathrm{Ca}^{2+}$ (van den Pol et al., 1992; Tominaga et al., 1994; Colwell, 2001). We next addressed the question of whether preventing $\mathrm{Ca}^{2+}$ influx by removing extracellular $\mathrm{Ca}^{2+}$ has a similar effect on SCN Perl expression as does hyperpolarizing the cells with low $\left[\mathrm{K}^{+}\right]$. We cultured $\mathrm{SCN}$ slices in different $\left[\mathrm{Ca}^{2+}\right]$ and found that, as with $\left[\mathrm{K}^{+}\right]$, the cyclic expression of Per1 was reversibly reduced or abolished in medium containing low $\left[\mathrm{Ca}^{2+}\right]$ (Fig. $3 A$ ). In addition, the period was shortened (24.2 \pm $0.30 \mathrm{~h}$ in $0.72 \mathrm{mM} \mathrm{Ca}^{2+}, n=5 ; 24.0 \pm 0.37 \mathrm{~h}$ in $0.54 \mathrm{mM} \mathrm{Ca}^{2+}, n=$ $4 ; p<0.05$; Student's $t$ test) compared with controls. Reversibility was demonstrated after $12 \mathrm{~h}(n=2), 18 \mathrm{~h}(n=4)$, and $24 \mathrm{~h}(n=4)$ in six separate explants cultured in $0 \mathrm{mM} \mathrm{Ca}^{2+}$ (Fig. S1, available at www.jneurosci.org as supplemental material). Lowering $\left[\mathrm{Ca}^{2+}\right] \mathrm{de}-$ polarized the membrane $(-43.8 \pm 2.85 \mathrm{mV}$ in $0 \mathrm{~mm} ;-48.5 \pm 2.53$ $\mathrm{mV}$ in $0.33 \mathrm{~mm}$ ), and increasing $\left[\mathrm{Ca}^{2+}\right]$ slightly hyperpolarized the neurons (Fig. $3 B)(-52.7 \pm 1.92 \mathrm{mV}$ in $3.36 \mathrm{~mm} ; n=11)$ compared with controls. To further demonstrate that the effect of low $\left[\mathrm{Ca}^{2+}\right]$ on the Per1-luc rhythm is oscillator specific and not caused by nonspecific effects, such as decreased cell viability or general transcription/translation, we added forskolin to SCN slices $(n=7)$ kept in 0 $\left[\mathrm{Ca}^{2+}\right]$, which transiently increases Per1-luc transcription in brain slices (Yamazaki et al., 2000; Abe et al., 2002). Forskolin markedly elevated the bioluminescence baseline in slices kept in medium containing $0\left[\mathrm{Ca}^{2+}\right]$ during $12,18,24$, and $48 \mathrm{~h}$, demonstrating that Per 1 transcription was functional in the explants (Fig. S2, available at www.jneurosci.org as supplemental material).

To examine the effects of low $\left[\mathrm{Ca}^{2+}\right]$ on Perl expression on non-neural tissues, we cultured liver tissue $(n=3)$ in various $\left[\mathrm{Ca}^{2+}\right]$. As with the SCN, low $\left[\mathrm{Ca}^{2+}\right]$ blunted or abolished the rhythm in Perl-luc expression (Fig. 3C).

\section{Blocking voltage-dependent $\mathrm{Ca}^{2+}$ conductances and buffering intracellular $\mathrm{Ca}^{2+}$ cease the rhythmic expression in Per1}

To analyze the role of voltage-dependent $\mathrm{Ca}^{2+}$ conductances in Per1 rhythmicity, we added $\mathrm{Ca}^{2+}$ channel blockers (specific to $\mathrm{N}$-, P-, Q-, L-, and T-types) to SCN slices cultured in control medium $(n=3)$. The channel blockers did not immediately abolish rhythmicity, but rather rhythms were lost after two to three cycles. As a control, slices $(n=4)$ were treated with equivalent $(0.1 \%)$ and higher concentrations of DMSO $(0.2,0.3$, and $0.4 \%)$, which had no effect on the Perl rhythm (Fig. 3D). DMSO at a very high concentration (4\%) did not affect the amplitude but shortened the period of the Per1 rhythm $(23.75 \pm 2.01 \mathrm{~h})$. None of the channel blockers alone led to arrhythmicity, although the L-type channel blocker nimodipine slightly reduced the amplitude of Per1 expression culture $(n=5)$ (Fig. S3, available at www.jneurosci.org as supplemental material). To further explore the role of $\mathrm{Ca}^{2+}$ in regulating Perl expression, in two different sets of experiments, we treated SCN cultures with the intracellular chelator BAPTA-AM. Buffering intracellular $\mathrm{Ca}^{2+}$ stopped Per1 rhythmicity at 40,80 , and $100 \mu \mathrm{M}$ but not at $20 \mu \mathrm{M}$ of original loading concentration of BAPTA-AM (Fig. 3E).

\section{The requirement of $\mathrm{Ca}^{2+}$ for Perl rhythmicity is not species- specific to rat}

To evaluate the generality of the $\mathrm{Ca}^{2+}$ requirement for the SCN Per1 rhythm, we performed similar experiments on SCN slices from a transgenic Per1-luc mouse. Mouse slices were cultured in control medium or $0 \mathrm{mM} \mathrm{Ca}^{2+}$ (defined as $0 \mathrm{mM} \mathrm{Ca}^{2+}$ added to the culture medium; $n=3$ ), and the rhythm in Per1-luc expression was recorded. In slices cultured in control medium, the Per1luc expression was rhythmic (period, $24.4 \pm 0.39 \mathrm{~h}$ ). However, similar to rat slices, the mouse Per1 rhythm was immediately abolished in $0 \mathrm{mM} \mathrm{Ca}^{2+}$, indicating that the $\mathrm{Ca}^{2+}$ requirement of molecular rhythmicity in the $\mathrm{SCN}$ is not species specific (Fig. $4 A$ ).

\section{$\mathrm{A} \mathrm{Ca}^{2+}$ flux is required also for PER2 rhythmicity}

We also evaluated whether $\mathrm{Ca}^{2+}$ is required for sustained rhythmicity of other clock genes and their protein products. We used slices from a Per $2^{\text {Luc }}$ knock-in mouse (provided by Dr. Joseph S. Takahashi), in which a PERIOD2:LUCIFERASE fusion protein is used as a real-time reporter. In control medium, the PER2:LUC protein showed a robust circadian expression (period, $23.9 \pm 0.21 \mathrm{~h} ; n=5$ ), as reported recently (Yoo et al., 2004). When we cultured slices in 0 $\mathrm{mM} \mathrm{Ca}^{2+}(n=4)$, similar to Per1, the PER2 protein rhythm was immediately attenuated and absent after two to three cycles (Fig. 4B). In addition, we treated PER2:LUC slices with $20 \mu \mathrm{M}(n=3)$ or $80 \mu \mathrm{M}$ $(n=3)$ loading concentration of BAPTA-AM, which, as for Per1, abolished the PER2:LUC rhythm (Fig. 4C).

\section{Discussion}

Our data provide the first demonstration of an ionic flux requirement for rhythms in molecular expression in mammals. These findings are consistent with the observations in Drosophila that electrical silencing stops the free-running circadian clock (Nitabach et al., 2002). Our experiments extend this observation to mammals and suggest that a transmembrane $\mathrm{Ca}^{2+}$ flux is essential for molecular rhythmicity. A critical role of $\mathrm{Ca}^{2+}$ influx in rhythm generation is supported by several observations. First, reducing the transmembrane flux by hyperpolarizing the membranes of pacemaker cells, and thereby presumably closing voltage-controlled $\mathrm{Ca}^{2+}$ conductances, leads to arrhythmicity in Perl expression. Second, removing extracellular $\mathrm{Ca}^{2+}$ abolishes 
A

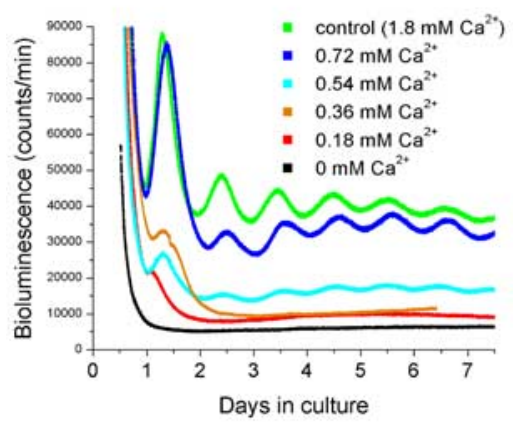

B

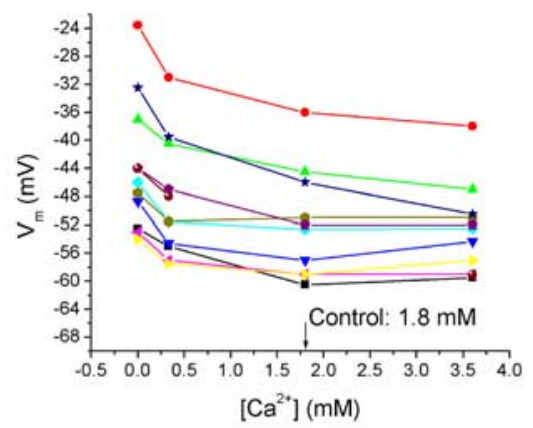

C

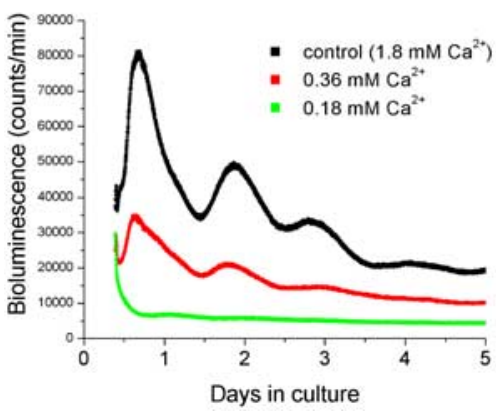

Figure 3. Recordings of membrane potential and bioluminescence in various concentrations of $\mathrm{Ca}^{2+} . \boldsymbol{A}$, Bioluminescence recordings from SCN explants obtained from transgenic Per 1 -luc rats. The explants were cultured in medium containing $0,0.18$, $0.36,0.54,0.72$, or $1.8 \mathrm{~mm}$ (control) $\mathrm{Ca}^{2+}$. $\boldsymbol{B}$, Current-clamp recordings in recording solutions containing $0,0.33,1.8$, and $3.36 \mathrm{~mm}$ $\mathrm{Ca}^{2+}$. Each color represents recorded membrane potentials in a single $\mathrm{SCN}$ neuron in various concentrations of $\mathrm{Ca}^{2+}$. C, Bioluminescence recordings from liver explants obtained from Per 1 -luc rats. Liver tissues were cultured in medium containing 0.18 , 0.36 , or $1.8 \mathrm{~mm} \mathrm{Ca}^{2+}$.D, Effect of $\mathrm{Ca}^{2+}$ channel antagonists on the SCN Per1-luc rhythm. SCN explants were cultured in control medium. After 3-5 din culture, a DMSO control (top trace) or a mixture of $\mathrm{Ca}^{2+}$ channel blockers specific to $\mathrm{N}-, \mathrm{P}-, \mathrm{Q}^{2}, \mathrm{~L}-$, and T-types (bottom trace) was added (indicated by arrows) to the explants. $\boldsymbol{E}$, The intracellular $\mathrm{Ca}^{2+}$ chelator BAPTA-AM $(20,40,80$, and $100 \mu \mathrm{M}$ ) was added to SCN explants, and bioluminescence was recorded. DMSO was added as a control.
A

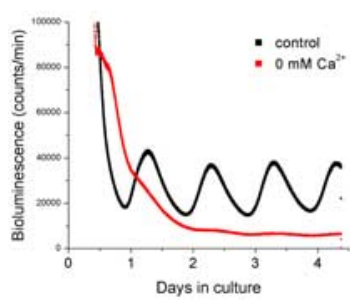

B

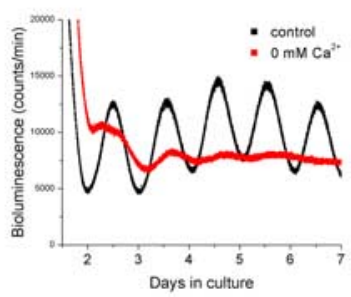

C

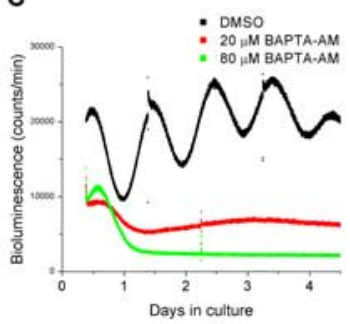

Figure 4. Bioluminescence recordings in mouse SCN explants. $\boldsymbol{A}$, Recordings of Per1-luc signals. The explants were cultured in 0 or $1.8 \mathrm{~mm}$ (control) $\mathrm{Ca}^{2+}$. $\boldsymbol{B}$, Recordings of PER2:LUC expression. Explants were cultured in 0 or $1.8 \mathrm{~mm} \mathrm{Ca}^{2+}$. $\boldsymbol{C}$, Recordings of PER2:LUC expression. Explants were cultured in DMSO control (0.3\%) and BAPTA-AM (20 or $80 \mu \mathrm{m})$. rhythms in Per1 and PER2. Third, blocking various $\mathrm{Ca}^{2+}$ channels results in aperiodicity after two to three cycles. We are uncertain why $\mathrm{Ca}^{2+}$ channel blockers do not immediately abolish rhythmicity; however, we suspect that these compounds fail to completely block $\mathrm{Ca}^{2+}$ flux, which may explain the relatively delayed effect. Fourth, the membrane-permeable form of BAPTA blocks rhythmicity of Per 1 and PER2. Finally, the phase of the mPer1 rhythm is delayed proportionally to the time spent in $0\left[\mathrm{~K}^{+}\right]$medium. This suggests that the molecular clock is stopped rather than the rhythm being "masked" by any effects of reducing extracellular $\mathrm{K}^{+}$or $\mathrm{Ca}^{2+}$ on the ability of the reporter gene to reliably express the state of Per 1 transcription. This result also makes it unlikely that a low-amplitude rhythm persists in the absence of $\mathrm{K}^{+}$or $\mathrm{Ca}^{2+}$, hidden within the noise level of the photomultiplier. Although we did not record the effects of manipulations with $\left[\mathrm{K}^{+}\right]$and $\left[\mathrm{Ca}^{2+}\right]$ in individual pacemaker cells, we think it is unlikely that the effects observed are caused by intercellular uncoupling insomuch as the action of most of our treatments on rhythmicity was rapid, within $24 \mathrm{~h}$. Although uncoupling would lead to phase scattering and apparent ensemble arrhythmicity, this typically occurs gradually over 5-7 d (Welsh et al., 2004).

The fact that a non-neural tissue, liver, also becomes arrhythmic in low $\left[\mathrm{Ca}^{2+}\right]$ suggests that the requirement for molecular rhythmicity extends beyond neuronal tissues. Indeed, hepatocytes contain $\mathrm{Ca}^{2+}$ channels that are mainly receptor activated but may also include voltageactivated $\mathrm{Ca}^{2+}$ channels (Sawanobori et al., 1989; Brereton et al., 1997).

Although previous studies show conflicting conclusions regarding the role of membrane electrical events and ion fluxes in mammalian rhythm generation (Schwartz et al., 1987; Shibata and Moore, 1987; Shibata et al., 1987; Welsh et al., 1995; Shinohara et al., 1998), our data are consistent with recent findings in mice lacking vasoactive intestinal polypeptide receptor subtype $2\left(\mathrm{VPAC}_{2}\right)$ receptors, which are activated by vasoactive intestinal polypeptide (VIP) and pituitary adenylate cyclase activating polypeptide. Mice missing the $\mathrm{VPAC}_{2}$ receptor are unable to maintain normal behavioral rhythmicity and rhythmic expression of Per1, Per2, and Cry1 (Harmar et al., 2002). These mice also fail to exhibit the midday peak in electrical activity that is characteristic of impulse rhythms from SCN brain slices (Cutler et al., 2003). Consistent with these 
results, VIP/peptide histidine isoleucine-deficient mice were found to exhibit profound abnormalities in locomotor rhythmicity (Colwell et al., 2003). These studies suggest an important requirement for the $\mathrm{VPAC}_{2}$ receptor in normal SCN rhythmicity. The reductions in spontaneous electrical activity in SCN neurons and the observation that these cells are capable of responding with high-impulse frequencies to stimulation suggest that loss of the $\mathrm{VPAC}_{2}$ receptor may alter the resting potential of SCN neurons (Harmar et al., 2002; Cutler et al., 2003). This situation may therefore be similar to Drosophila (Nitabach et al., 2002), in which expression of Drosophila open rectifier $\mathrm{K}^{+}$channels in the pigment dispersing factor-expressing lateral neurons leads to a loss of behavioral and molecular rhythmicity through presumptive hyperpolarization of the membrane potential. A recent study, however, calls into question whether the lack of VIP/VPAC ${ }_{2}$ alters the SCN membrane potential. Aton et al. (2005) reported that dispersed arrhythmic SCN neurons from Vip ${ }^{-/-}$and Vipr $2^{-/-}$mice exhibited normal frequencies of spontaneous impulse activity, suggesting that loss of rhythmicity may not involve hyperpolarization. The basis of the discrepancy between the different studies using VIP/ $\mathrm{VPAC}_{2}$-deficient mice is presently unclear.

Another study measuring Perl-luc activity within single neurons in a slice (Yamaguchi et al., 2003) supports the view that membrane electrical activity is critical for circadian rhythmicity. When SCN slices were exposed to TTX, Perl rhythmicity damped immediately in individual neurons. Furthermore, TTX treatment caused decreased levels of Per 1 and Per 2 transcripts and proteins.

In a previous study, Ikeda et al. (2003) demonstrated a TTXresistant circadian rhythm in cytosolic, but not nuclear, $\mathrm{Ca}^{2+}$ concentration. These data are not necessarily at variance with our findings. It may indicate that there are two rhythmic systems: one membrane-related electrical rhythm and one intracellular cytosolic $\mathrm{Ca}^{2+}$ rhythm. Whether the cytosolic $\mathrm{Ca}^{2+}$ rhythm affects clock gene rhythms or vice versa has not yet been determined and additional experiments are required to investigate the relationship between molecular, electrical, and intracellular $\mathrm{Ca}^{2+}$ rhythms. Another possibility is that TTX does not block rhythmic membrane oscillations that lead to periodic $\mathrm{Ca}^{2+}$ influx. A more direct experiment would therefore be to test whether the cytosolic $\mathrm{Ca}^{2+}$ rhythm persists in hyperpolarizing or low $\left[\mathrm{Ca}^{2+}\right]$ medium.

As shown in our previous studies in the invertebrate Bulla model (McMahon and Block, 1987), a transmembrane $\mathrm{Ca}^{2+}$ flux may also play a major role in entrainment of the mammalian pacemaker. This has been demonstrated recently in the SCN by Kim do et al. (2005), who showed that voltage-gated $\mathrm{Ca}^{2+}$ channels are required for glutamate-induced phase shifts.

The findings described in our study strengthen the view about the importance of membrane electrical phenomena and directly implicate $\mathrm{Ca}^{2+}$ influx in rhythm generation. Important issues remain about the nature of the required $\mathrm{Ca}^{2+}$ influx (e.g., single cell recordings; restricted to specific circadian phases) and intracellular targets of the flux required for sustained molecular rhythmicity.

\section{References}

Abe M, Herzog ED, Yamazaki S, Straume M, Tei H, Sakaki Y, Menaker M, Block GD (2002) Circadian rhythms in isolated brain regions. J Neurosci 22:350-356.

Aton SJ, Colwell CS, Harmar AJ, Waschek J, Herzog ED (2005) Vasoactive intestinal polypeptide mediates circadian rhythmicity and synchrony in mammalian clock neurons. Nat Neurosci 8:476-483.

Block GD, Khalsa SB, McMahon DG, Michel S, Geusz M (1993) Biological clocks in the retina: cellular mechanism of biological timekeeping. Int Rev Cytol 146:83-144.

Brereton HM, Harland ML, Froscio M, Petronijevic T, Barritt GJ (1997) Novel variants of voltage-operated calcium channel alpha 1-subunit tran- scripts in a rat liver-derived cell line: deletion in the IVS4 voltage sensing region. Cell Calcium 22:39-52.

Colwell CS (2001) NMDA-evoked calcium transients and currents in the suprachiasmatic nucleus: gating by the circadian system. Eur J Neurosci 13:1420-1428.

Colwell CS, Michel S, Itri J, Rodriguez W, Tam J, Lelievre V, Hu Z, Liu X, Waschek JA (2003) Disrupted circadian rhythms in VIP and PHI deficient mice. Am J Physiol Regul Integr Comp Physiol 285:R939-R949.

Cutler DJ, Haraura M, Reed HE, Shen S, Sheward WJ, Morrison CF, Marston HM, Harmar AJ, Piggins HD (2003) The mouse VPAC2 receptor confers suprachiasmatic nuclei cellular rhythmicity and responsiveness to vasoactive intestinal polypeptide in vitro. Eur J Neurosci 17:197-204.

Dunlap JC (1999) Molecular bases for circadian clocks. Cell 96:271-290.

Harmar AJ, Marston HM, Shen S, Spratt C, West KM, Sheward WJ, Morrison CF, Dorin JR, Piggins HD, Reubi JC, Kelly JS, Maywood ES, Hastings MH (2002) The VPAC(2) receptor is essential for circadian function in the mouse suprachiasmatic nuclei. Cell 109:497-508.

Ikeda M, Sugiyama T, Wallace CS, Gompf HS, Yoshioka T, Miyawaki A, Allen CN (2003) Circadian dynamics of cytosolic and nuclear $\mathrm{Ca}^{2+}$ in single suprachiasmatic nucleus neurons. Neuron 38:253-263.

Kim do Y, Choi HJ, Kim JS, Kim YS, Jeong do U, Shin HC, Kim MJ, Han HC, Hong SK, Kim YI (2005) Voltage-gated calcium channels play crucial roles in the glutamate-induced phase shifts of the rat suprachiasmatic circadian clock. Eur J Neurosci 21:1215-1222.

McMahon DG, Block GD (1987) The Bulla circadian pacemaker: I. Pacemaker neuron membrane potential controls phase through a calciumdependent mechanism. J Comp Physiol 161:335-346.

Meijer JH, Schwartz WJ (2003) In search of the pathways for light-induced pacemaker resetting in the suprachiasmatic nucleus. J Biol Rhythms 18:235-249.

Moore RY (1991) The suprachiasmatic nucleus and the circadian timing system. In: Suprachiasmatic nucleus-the mind's clock (Klein D, Moore R, Reppert S, eds), pp 13-15. New York: Oxford UP.

Nitabach MN, Blau J, Holmes TC (2002) Electrical silencing of Drosophila pacemaker neurons stops the free-running circadian clock. Cell 109:485-495.

Sawanobori T, Takanashi H, Hiraoka M, Iida Y, Kamisaka K, Maezawa H (1989) Electrophysiological properties of isolated rat liver cells. J Cell Physiol 139:580-585.

Schaap J, Pennartz CM, Meijer JH (2003) Electrophysiology of the circadian pacemaker in mammals. Chronobiol Int 20:171-188.

Schwartz WJ, Gross RA, Morton MT (1987) The suprachiasmatic nuclei contain a tetrodotoxin-resistant circadian pacemaker. Proc Natl Acad Sci USA 84:1694-1698.

Shibata S, Moore RY (1987) Development of neuronal activity in the rat suprachiasmatic nucleus. Brain Res 431:311-315.

Shibata S, Newman GC, Moore RY (1987) Effects of calcium ions on glucose utilization in the rat suprachiasmatic nucleus in vitro. Brain Res 426:332-338.

Shinohara K, Honma S, Katsuno Y, Abe H, Honma K (1998) Circadian release of amino acids in the suprachiasmatic nucleus in vitro. NeuroReport 9:137-140.

Tominaga K, Geusz ME, Michel S, Inouye ST (1994) Calcium imaging in organotypic cultures of the rat suprachiasmatic nucleus. NeuroReport 5:1901-1905

van den Pol AN, Finkbeiner SM, Cornell-Bell AH (1992) Calcium excitability and oscillations in suprachiasmatic nucleus neurons and glia in vitro. J Neurosci 12:2648-2664.

Welsh DK, Logothetis DE, Meister M, Reppert SM (1995) Individual neurons dissociated from rat suprachiasmatic nucleus express independently phased circadian firing rhythms. Neuron 14:697-706.

Welsh DK, Yoo SH, Liu AC, Takahashi JS, Kay SA (2004) Bioluminescence imaging of individual fibroblasts reveals persistent, independently phased circadian rhythms of clock gene expression. Curr Biol 14:2289-2295.

Yamaguchi S, Isejima H, Matsuo T, Okura R, Yagita K, Kobayashi M, Okamura H (2003) Synchronization of cellular clocks in the suprachiasmatic nucleus. Science 302:1408-1412.

Yamazaki S, Numano R, Abe M, Hida A, Takahashi R, Ueda M, Block GD, Sakaki Y, Menaker M, Tei H (2000) Resetting central and peripheral circadian oscillators in transgenic rats. Science 288:682-685.

Yoo SH, Yamazaki S, Lowrey PL, Shimomura K, Ko CH, Buhr ED, Siepka SM, Hong HK, Oh WJ, Yoo OJ, Menaker M, Takahashi JS (2004) PERIOD2: LUCIFERASE real-time reporting of circadian dynamics reveals persistent circadian oscillations in mouse peripheral tissues. Proc Natl Acad Sci USA 101:5339-5346. 